\title{
PENGARUH STRATEGI E-MARKETING DAN VARIASI PRODUK TERHADAP MINAT BELI KONSUMEN MA. Baidowi ${ }^{1}$, \\ ${ }^{1,}$ Dosen jurusan Manajemen, Universitas Tridinanti, Sumatera Selatan \\ ${ }^{1)}$ Email : baidowipalembang2016@gmail.com
}

\section{Submitted: \\ $06 / 01 / 2021$ \\ Revised: \\ $25 / 05 / 2021$ \\ Accepted: \\ $27 / 06 / 2021$ \\ Online-Published: \\ $30 / 06 / 2021$}

INFORMASI ARTIKEL

\begin{abstract}
ABSTRAK
Tujuan penelitian ini adalah untuk mengetahui Pengaruh Strategi EMarketing dan Variasi Produk terhadap Minat Beli Konsumen Produk Herbal HNI HPAI BC 1 Cabang Palembang.

Variabel yang digunakan dalam penelitian ini, Strategi E-Marketing (X1), Variasi Produk (X2), Minat Beli Konsumen (Y). Populasi dalam penelitian ini adalah 75 pelanggan HNI HPAI BC 1 Cabang Palembang yang membeli Produk Herbal HNI HPAI BC 1 Cabang Palembang. Jenis penelitian ini adalah kuantitatif. Teknik analisis yang digunakan adalah regresi linier berganda, pengujian hipotesis menggunakan uji $F$ dan uji $t$.

Hasil regresi diperoleh persamaan $Y=3,695+0,589 X 1+0,299 X 2$. Artinya Minat Beli Konsumen dipengaruhi oleh Strategi E-Marketing dan Variasi Produk. Hasil uji F diperoleh Fhitung (480.870), artinya ada pengaruh Strategi E-Marketing dan Variasi Produk secara simultan terhadap Minat Beli Konsumen. Hasil uji $t$ untuk variabel Strategi E-Marketing diperoleh thitung (10,583), dan variabel Variasi Produk diperoleh thitung (4,520) yang berarti Strategi E-Marketing dan Variasi Produk berpengaruh secara parsial terhadap Minat Beli Konsumen pada membeli Produk Herbal HNI HPAI BC 1 Cabang Palembang.
\end{abstract}

Kata Kunci: Strategi E-Marketing, Variasi Produk, dan Minat Beli Konsumen

\section{ABSTRACK}

The purpose of this study was to determine the effect of E-Marketing Strategy and Product Variation on Consumer Purchase Interest in buying Herbal Products HNI HPAI BC 1 Palembang Branch. The variables used in this study, E-Marketing Strategy (X1), Product Variation (X2), Consumer Purchase Interest $(Y)$. The population in this study were 75 customers of HNI HPAI BC 1 Palembang Branch who bought Herbal Products HNI HPAI BC 1 Palembang Branch. This type of research is quantitative. The analysis technique used is multiple linear regression, hypothesis testing using the F test and t test.

The regression results obtained the equation $Y=3.695+0.589 X 1+$ 0.299 X2. Which means that Consumer Purchase Interest is influenced by EMarketing Strategies and Product Variations. The results of the F test obtain Fcount (480,870), meaning that there is an effect of E-Marketing Strategy and Product Variation simultaneously on Consumer Purchase Intention. The results of the $t$ test for the E-Marketing Strategy variable obtained tcount (10.583), and the Product Variation variable obtained tcount (4.520), which means that the E-Marketing Strategy and Product Variation had a partial effect on Consumer Purchase Interest in buying Herbal Products HNI HPAI BC 1 Palembang Branch.

Keywords: E-Marketing Strategy, Product Variation, and Consumer Purchase Interest

\section{A. PENDAHULUAN}

\begin{tabular}{lcrr}
\multicolumn{2}{r}{ Marketing } & atau & pemasaran \\
merupakan & alat & untuk & menyampaikan \\
informasi atau teori yang digunakan
\end{tabular}

pengusaha untuk mengenalkan suatu produk kepada masyarakat agar produk tersebut bisa dikenal oleh masayarakat luas, setelah masyarakat mengenal produk tersebut per usahaan harus mempunyai ke unggulan 
bersaing guna menghadapi berbagai ancaman yang ada di pasar.

Selain itu untuk meningkatkan keunggulan bersaing perusahaan juga harus mengambil kesempatan dalam memanfaatkan teknologi informasi yang berkembang saat ini dalam meningkatkan minat beli konsumen. Salah satunya adalah dengan strategi marketing yang marak digunakan perusahaan diarus globalisasi ini ialah strategi e-marketing (electronic marketing) atau biasa di sebut dengan pemasaran secara online menggunakan media internet.

Salah satu perusahaan yang menggunakan strategi e-marketing adalah PT Herba Penawar Alwahida Indonesia (HPAI) yaitu perusahaan yang bergerak di bidang Usaha Perdagangan Produk herbal. HPAI ini didirikan pada tanggal 19 Maret 2012 dengan tujuan untuk memberi pengajaran mengenai pengobatan herbal sebagai bentuk layanan kesehatan yang terjamin kehalalanya.

\section{E-Marketing}

Menurut Chaffey (2009:417), “ $E$ Marketing mencapai tujuan pemasaran melalui penggunaan komunikasi teknologi elektronik". E-Marketing (Electronic Marketing) merupakan suatu proses pemasaran yang menggunakan teknologi komunikasi elektronik, khususnya internet. E-Marketing mengacu pada perspektif external bagaimana internet dapat digunakan bersama dengan media sosial untuk mendapatkan dan memberikan layanan kepada pelanggan. (Chaffey, 2009:87).

Sederhananya definisi e-marketing adalah hasil dari teknologi informasi yang diterapkan untuk strategi pemasaran. Namun, e-marketing melibatkan teknologi dasar dan aplikasi. Berdasarkan ketiga pen-dapat diatas dapat disimpulkan, e-marketing merupakan pemasaran elektronik yang memanfaatkan per-kembangan teknologi informasi sebagai alat untuk memasarkan suatu produk berupa barang, jasa, informasi ataupun ideide melalui komunikasi teknologi internet serta alat-alat komunikasi lainnya.

\section{Variasi Produk}

$$
\text { Menurut Kotler }
$$

mendefinisikan "variasi produk sebagai unit tersendiri dalam suatu merek atau lini produk yang dapat dibedakan berdasarkan ukuran, harga, atau suatu ciri lain. Semakin beragamnya jumlah dan jenis produk yang dijual disuatu tempat maka konsumen akan merasa puas dan melakukan pembelian pada produk tersebut dan ia tidak perlu melakukan pembelian produk lain. Hal tersebut menunjukkan bahwa variasi produk dapat meningkatkan keputusan pembelian konsumen.

Menurut Mikell P. Groover (2010:6) dalam Journal of Business Management and Enterpreneurship Education mengatakan bahwa variasi produk dapat diartikan sebagai produk yang memiliki desain atau jenis yang berbeda dan diproduksi oleh perusahaan.

Variasi produk merupakan yang membedakan produk antara perusahaan dikategori produk yang sama. Variasi produk yang dilakukan untuk meningkatkan penjualannya, variasi tersebut dapat dilakukan dengan berbagai cara berupa variasi ukuran, harga, tampilan, dan bahanbahan yang merupakan komponen dari variasi produk yang dapat dijadikan pembeda dengan produk pesaing

\section{Minat Beli}

Menurut Kotler ( Melani, 2016 : 10 ) Minat adalah pengambilan keputusan untuk membeli atas satu alternatif merek diantara berbagai alternatif lainya.

Minat membeli ini muncul setelah melalui serangkaian proses yaitu : pengenalan kebutuhan, pencarian informasi, evaluasi informasi, sehingga timbul minat.

Sedangkan menurut Yamit (Melani, 2016:10) minat merupakan evaluasi purna beli atau hasil evaluasi setelah membandingkan apa yang dirasakan dengan harapannya"

Jadi minat beli merupakan dorongan yang timbul dalam diri seseorang untuk membeli barang dan jasa dalam rangka pemenuhan kebutuhan.

\section{B. METODE PENELITIAN}

Penelitian ini menggunakan metode survei, dengan model pengujian deskriptif, yang dilaksanakan melalui pengumpulan data di lapangan terhadap para.

konsumen HNI HPAI BC 1 Cabang Palembang, penetapan jumlah sampel dengan 
menggunakan sampel jenuh Suharsimi Arikunto, (1993:104) yaitu bila jumlah populasi kurang dari 100, maka semuanya dijadikan sampel dan jika lebih dari 100 maka diambil sampel sebanyak $10-15 \%$ atau 20-25\%, jumlah sampel sebayak 75 orang . Variabel yang diamati dalam penelitian ini terdiri dari Strategi E-Marketing.

(X1) dan Variasi Produk (X2) sebagai variabel independen minat beli $(\mathrm{Y})$ sebagai variabel dependen. Untuk mengukur Strategi E-Marketing (X1) dan Variasi Produk (X2) sebagai variabel, maka penelitian ini menggunakan dimensi yang terdiri: Website, Sosial Media, dengan indikator Promosi secara online, pemesanan secara online, transaksi secara online dan pelayanan secara online untuk mengukur variabel Variasi Produk digunakan Dimensi yang terdiri dari : kualitas produk, kemasan, bentuk dan desain, komposisi , dengan indikator ukuran, harga, tampilan.
Sedangkan untuk mengukur Minat beli sebagai variabel digunakan dimensi : perhatian, minat, kehendak, tindakan dengan indikator : minat transaksional, minat refresial, minat prefensial, minat eksploratif. Teknik analisis penelitian ini menggunakan analisis korelasi dan regresi linear berganda, sedangkan pengujian hipotesis digunakan uji koefisien determinasi (R2), uji $t$ dan uji $F$ (Sugiyono 2014).

\section{HASIL DAN PEMBAHASAN}

\section{Hasil Uji Regresi}

Untuk mengetahui pengaruh kualitas pelayanan terhadap kepuas-an pembeli, maka dilakukan analisis model regresi linier berganda. Analisis ini menggunakan program SPSS 22 untuk lebih jelasnya hasil analisis regresi linier berganda disajikan pada tabel.berikut ini.

Tabel 1

\section{Hasil Aanalisis Regresi Linier Berganda}

Coefficients $^{\mathrm{a}}$

\begin{tabular}{|c|c|c|c|c|c|c|}
\hline \multirow{2}{*}{\multicolumn{2}{|c|}{ Model }} & \multicolumn{2}{|c|}{$\begin{array}{c}\text { Unstandardized } \\
\text { Coefficients }\end{array}$} & \multirow{2}{*}{$\begin{array}{c}\text { Standardized } \\
\text { Coefficients } \\
\text { Beta }\end{array}$} & \multirow[b]{2}{*}{$\mathrm{t}$} & \multirow[b]{2}{*}{ Sig. } \\
\hline & & B & Std. Error & & & \\
\hline \multirow[t]{3}{*}{1} & (Constant) & 3,695 & 1,090 & & 3,392 & ,001 \\
\hline & Strategi E-Marketing (X1) &, 589 &, 056 & ,694 & 10,583 &, 000 \\
\hline & Variasi Produk (X2) & 299 & ,066 & ,296 & 4,520 & ,000 \\
\hline
\end{tabular}

a. Dependent Variable: Minat Beli (Y)

Berdasarkan tabel diatas dapat diketahui hasil analisis regresi linier berganda sebagai berikut :

$Y=a+b_{1} X_{1}+b_{2} X_{2}+e$

$Y=3,695+0,589 X 1+0,299 X_{2}+e$

Dimana :

Y : Variabel Minat Beli Konsumen

a : Konstanta

$\mathrm{X}_{1} \quad$ : Strategi E-Marketing

$\mathrm{X}_{2} \quad$ : Variasi Produk

$\mathrm{b}_{1}, \mathrm{~b}_{2} \quad$ : Koefesien Regresi

e : Faktor Lain

Dan dari persamaan regresi tersebut dapat dijelaskan sebagai berikut :

1. Nilai konstant (a) adalah menunjukan besarnya nilai Minat Beli Konsumen (Y).
Hal ini menyatakan bahwa jika variabel Strategi E-Marketing dan Variasi Produk dianggap konstant atau $=0$, maka nilai Minat Beli sebesar 3,695.

2. Koefesien Regresi Strategi E-Marketing $\left(b_{1}\right)$ sebesar 0,589 hasil tersebut dapat diartikan bahwa setiap peningkatan harga sebesar $100 \%$ maka akan mengakibatkan peningkatan minat beli konsumen sebesar $58,9 \%$.

3. Koefesien regresi Variasi Produk $\left(b_{2}\right)$ sebesar 0,299 hasil tersebut dapat dartikan bahwa setiap peningkatan minat beli sebesar $100 \%$ maka akan mengakibatkan peningkatan minat beli konsumen sebesar $29,9 \%$

Dilihat dari persamaan $\mathbf{Y}=\mathbf{3 , 6 9 5}+$

$0,589 X_{1}+0,299 X_{2}+e$ maka pengaruh yang paling dominan / besar terhadap Minat Beli 
Konsumen (Y) berasal dari Strategi EMarketing $\left(\mathrm{X}_{1}\right)$.

\section{Hasil Pengujian Koefesien Korelasi}

Hasil penelitian antara Variabel Strategi E-Marketing $\left(\mathrm{X}_{1}\right)$ dan Variabel Variasi Produk $\left(\mathrm{X}_{2}\right)$ dengan Variabel Minat Beli (Y) dapat dilihat dari hasil analisis Model Sumary pada tabel 2. disajikan pada tabel di bawah ini :

Tabel 2

\section{Hasil Uji Koefesien Korelasi}

Model Summary
\begin{tabular}{|l|c|r|r|r|}
\hline Model & R & R Square & Adjusted R Square & $\begin{array}{c}\text { Std. Error of the } \\
\text { Estimate }\end{array}$ \\
\hline 1 &, $965^{\mathrm{a}}$ &, 930 &, 928 & 1,713 \\
\hline
\end{tabular}

a. Predictors: (Constant), Variasi Produk (X2), Strategi E-Marketing (X1)

b. Dependent Variable: Minat Beli (Y)

Berdasarkan tabel 2. diatas diperoleh hasil analisis korelasi antar Strategi EMarketing $\left(\mathrm{X}_{1}\right)$ dan Variabel Variasi Produk $\left(\mathrm{X}_{2}\right)$ dengan Variabel Minat Beli (Y) nilai R sebesar 0,965 atau $96,5 \%$, artinya keeratan hubungan Strategi E-Marketing $\left(\mathrm{X}_{1}\right)$ dan Variabel Variasi Produk $\left(\mathrm{X}_{2}\right)$ dengan Variabel Minat Beli (Y) tergolong sangat kuat karena berada di kisaran 0,80-1,000 .

\section{Hasil Pengujian Koefesien Determinasi $\left(\mathbf{R}^{2}\right)$ \\ Uji Koefesien Determinasi $\left(\mathrm{R}^{2}\right)$} bertujuan untuk mengetahui seberapa besar kemampuan Strategi E-Marketing $\left(\mathrm{X}_{1}\right)$ dan Variasi Produk $\left(\mathrm{X}_{2}\right)$ menjelaskan variabel Minat Beli (Y) secara keseluruhan pada tabel model summary berikut ini :

Tabel 3.

\section{Hasil Uji Koefesien Determinasi $\left(\mathbf{R}^{2}\right)$}

Model Summary ${ }^{\mathrm{b}}$

\begin{tabular}{|l|r|r|r|r|}
\hline Model & \multicolumn{1}{|c|}{$\mathrm{R}$} & \multicolumn{1}{|c|}{ R Square } & Adjusted R Square & \multicolumn{2}{c|}{ Estimate } \\
\hline 1 &, $965^{\mathrm{a}}$ &, 930 &, 928 & 1,713 \\
\hline
\end{tabular}

a. Predictors: (Constant), Variasi Produk (X2), Strategi E-Marketing (X1)

b. Dependent Variable: Minat Beli (Y)

Berdasarkan tabel 3 tersebut diatas. diperoleh nilai koefesien $\mathrm{R}^{2}$ sebesar 0,930 atau $93,0 \%$. Nilai $R$ square $\left(\mathrm{R}^{2}\right) \quad 93,0 \%$, ini menunjukan bahwa variabel Minat Beli yang dapat dijelaskan oleh variabel Strategi E-Marketing dan Variasi Produk adalah sebesar 93,0 \%, sedangkan sisanya sebesar 0,070 atau $7 \%$ dijelaskan oleh faktor-faktor lain diluar penelitian ini.

\section{Uji Hipotesis}

\section{Hasil Uji Simultan (Uji F)}

Uji F dikenal dengan Uji srimultan atau

Uji Anova, yaitu uji untuk melihat bagaimanakah pengaruh variabel bebas secara bersama-sama terhadap variabel terikat atau untuk menguji apakah model regresi yang dibuat signifikan atau tidak signifikan. Pada pengujian ini juga menggunakan tingkat signifikasi sebesar 0,5 $(\alpha=5 \%)$. Prosedur uji F ini adalah sebagai berikut :

a. Menentukan hipotesis nol maupun hipotesis alternatifnya :

Ho : $b_{1}, b_{2}=0$, artinya tidak ada pengaruh strategi e-marketing dan variasi produk terhadap minat beli 
konsumen (studi pada produk herbal HNI HPAI BC 1 Cabang Palembang).

$\mathrm{Ha}: \mathrm{b}_{1}, \mathrm{~b}_{2} \neq 0$ artinya terdapat pengaruh strategi e-marketing dan variasi produk terhadap minat beli konsumen (studi pada produk herbal HNI HPAI BC 1 Cabang Palembang).

b. Menentukan level of significant $(\alpha)=$ 0,05

c. Kriteria pengujian Uji F :

1. Terima Ho, jika sig $F \geq 0,05$ dan menolak Ha

2. Tolak Ho, sig $\mathrm{F}<0,05$ dan menerima $\mathrm{Ha}$ d. Kesimpulan : menerima atau menolak Ho dan menerima atau menolak $\mathrm{Ha}$.

Hipotesis penelitian yang perlu diuji adalah Strategi E-Marketing dan Variasi Produk berpengaruh secara signifikan terhadap Minat Beli Konsumen. Hasil uji simultan diperoleh nilai $F_{\text {sig }}$ sebesar 0,000 berarti nilai $\mathrm{F}_{\text {sig }}<0,05$. Karena itu, secara keseluruhan atau secara bersama-sama variabel Strategi E-Marketing dan Variasi Produk berpengaruh positif dan signifikan terhadap Minat Beli Konsumen, dapat dilihat pada tabel 4. dibawah ini.

\section{Tabel 4}

\section{Hasil Uji F}

ANOVA $^{\mathrm{a}}$

\begin{tabular}{|ll|l|l|l|l|l|}
\hline Model & & Sum of Squares & df & Mean Square & F & Sig. \\
\hline 1 & Regression & 2821,268 & 2 & 1410,634 & 480,870 &, $000^{6}$ \\
& Residual & 211,212 & 72 & 2,934 & & \\
& Total & 3032,480 & 74 & & & \\
\hline
\end{tabular}

a. Dependent Variable: Minat Beli (Y)

b. Predictors: (Constant), Variasi Produk (X2), Strategi E-Marketing (X1)

Berdasarkan hasil output SPSS di atas kita dapat melihat dimana nilai $\mathrm{F}$ hitung $(480,870)$ lebih besar dari pada nilai $F$ tabel $(3,12)$ dengan tingkat signifikan dibawah 0,05 yaitu 0,000 . Atas dasar ini, maka hipotesis penelitian yang diajukan sebelumnya dapat diterima karena terbukti kebenaranya (Ha diterima dan Ho di tolak).

\section{Hasil Uji Parsial (Uji t)}

Uji t dikenal dengan uji parsial, yaitu untuk menguji bagaimana pengaruh masing-masing variabel bebas secara sendiri-sendiri terhadap variabel terikat. Pengujian hipotesis akan dilakukan dengan mengguna-kan tingkat sigfinikasi sebesar $0,05(\alpha=5 \%)$ atau tingkat keyakinan sebesar 0,95 .

a. Menentukan hipotesis nol mau-pun hipotesis alternatifnya :

1. Pengaruh Strategi E-Marketing $\left(\mathrm{X}_{1}\right)$ terhadap Minat Beli Konsumen Y
Ho : $\mathrm{b}_{1}=0$, tidak terdapat pengaruh positif $\mathrm{X}_{1}$ terhadap $\mathrm{Y}$ $\mathrm{Ha}: \mathrm{b}_{1} \neq 0$,terdapat pengaruh positif $\mathrm{X}_{1}$ terhadap $\mathrm{Y}$

2. Pengaruh Variasi Produk $\left(\mathrm{X}_{2}\right)$ terhadap Minat Beli Konsumen $\mathrm{Y}$

Ho : $\mathrm{b}_{2}=0$, tidak terdapat pengaruh positif $\mathrm{X}_{2}$ terhadap $\mathrm{Y}$

$\mathrm{Ha}: \mathrm{b}_{2} \neq 0$, terdapat pengaruh positif $\mathrm{X}_{2}$ terhadap $\mathrm{Y}$

b. Menentukan level of significant $(\alpha)=$ 0,05

c. Ketentuan dalam pengujian ini adalah sebagai berikut

1. Terima Ho, jika sig $\mathrm{t} \geq 0,05$ dan menolak Ha

2. Tolak Ho, jika sig $\mathrm{t}<0,05$ dan menerima $\mathrm{Ha}$

d. Kesimpulan : menerima atau menolak Ho dan menerima atau menolak Ha. 
Hasil analisis regresi yang interprestasikan sebagai berikut : diringkas seperti pada tabel 5 dapat di

Tabel 5.

Hasil Uji t

Coefficients $^{\mathrm{a}}$

\begin{tabular}{|ll|r|r|r|r|r|}
\hline \multirow{2}{*}{ Model } & \multicolumn{2}{|c|}{$\begin{array}{c}\text { Unstandardized } \\
\text { Coefficients }\end{array}$} & \multicolumn{1}{c|}{$\begin{array}{c}\text { Standardized } \\
\text { Coefficients }\end{array}$} & & \multirow{2}{*}{} \\
\cline { 2 - 4 } & \multicolumn{1}{|c|}{ B } & Std. Error & \multicolumn{1}{c|}{ Beta } & \multicolumn{1}{c|}{ Sig. } \\
\hline 1 & (Constant) & 3,695 & 1,090 & & 3,392 &, 001 \\
& Strategi E-Marketing (X1) &, 589 &, 056 &, 694 & 10,583 &, 000 \\
& Variasi Produk (X2) &, 299 &, 066 &, 296 & 4,520 &, 000 \\
\hline
\end{tabular}

a. Dependent Variable: Minat Beli (Y)

Berdasarkan hasil output SPSS di atas kita dapat melihat Bahwa :

1. Nilai pengaruh Variabel $\mathrm{X}_{1}$ (Strategi E-Marketing) terhadap Minat Beli Konsumen di peroleh nilai $\mathrm{t}$ hitung 10,583 dengan nilai signifikansi sebesar $\mathrm{t}_{\text {sig }}=0,000$ yang berarti lebih kecil dari nilai $\alpha=0,05$. Strategi EMarketing $\left(\mathrm{X}_{1}\right)$ secara parsial berpengaruh nyata terhadap Minat Beli Konsumen (Y)

2. Nilai pengaruh Variabel $\mathrm{X}_{2}$ (Variasi Produk) terhadap Minat Beli Konsumen di peroleh nilai $\mathrm{t}$ hitung 4,520 dengan nilai signifikansi sebesar $\mathrm{t}_{\text {sig }}=0,000$ yang berarti lebih kecil dari nilai $\alpha=0,05$. Variasi Produk $\left(\mathrm{X}_{2}\right)$ secara parsial berpengaruh nyata terhadap Minat Beli Konsumen (Y)

\section{SIMPULAN DAN SARAN \\ 1. Simpulan}

Penelitian ini bertujuan untuk mengetahui pengaruh Strategi EMarketing dan Variasi Produk Terhadap Minat Beli Konsumen (Studi Pada Produk Herbal HNI HPAI BC 1 Cabang Palembang), maka dapat ditarik kesimpulan sebagai berikut :

1. Secara bersama-sama (simultan) terdapat pengaruh signifikan dari variabel Strategi E-Marketing dan Variasi Produk Terhadap Minat Beli Konsumen (Studi Pada Produk Herbal HNI HPAI BC 1 Cabang Palembang) dimana Nilai F hitung $(480,870)$ lebih besar dari pada nilai $F$ tabel $(3,12)$ dengan tingkat signifikan dibawah 0,05 yaitu 0,000 . Atas dasar ini, maka hipotesis penelitian yang diajukan sebelumnya dapat diterima karena terbukti kebenaranya (Ha diterima dan Ho di tolak).

2. Secara parsial Nilai pengaruh variabel $\mathrm{X}_{1}$ (StartegiE-Marketing) terhadap Minat Beli Konsumen diperoleh nilai nilai $t$ hitung 10,583 dengan nilai signifikansi sebesar $t_{\text {sig }}=0,000$ yang berarti lebih kecil dari nilai $\alpha=0,05$. Strategi E-Marketing $\left(\mathrm{X}_{1}\right)$ secara parsial berpengaruh nyata terhadap Minat Beli Konsumen (Y). Nilai engaruh variabel $\mathrm{X}_{2}$ (Variasi Produk) terhadap Minat Beli Konsumen diperoleh nilai $\mathrm{t}$ hitung $\mathrm{t}$ hitung 4,520 dengan nilai signifikansi sebesar $\mathrm{t}_{\mathrm{sig}}=$ 0,000 yang berarti lebih kecil dari nilai $\alpha=0,05$. Variasi Produk $\left(\mathrm{X}_{2}\right)$ secara parsial berpengaruh nyata terhadap Minat Beli Konsumen (Y)

3. Diperoleh korfesien determinasi $\left(\mathrm{R}^{2}=\right.$ 0,930). Hasil ini secara statistik sangat signifikan artinya 93,0 \% secara bersama-sama dapat menjelaskan pengaruh variabel Strategi E-Marketing $\left(\mathrm{X}_{1}\right)$ dan Variasi Produk $\left(\mathrm{X}_{2}\right)$ Terhadap Minat Beli Konsumen, sedangkan sisanya sebesar 0,070 atau $7 \%$ dijelaskan oleh faktor-faktor lain diluar penelitian ini. 


\section{Saran}

Berdasarkan kesipulan hasil penelitian, maka penulis menyampaikan beberapa saran sebagai bahan pertimbangan pada pihak-pihak yang terkait dalam penelitian ini. Sebagai berikut :

1. Stategi pemasaran secara online yang dilakukan PT Herba Penawar Alwahida Indonesia selama ini harus ditingkatkan lagi, dengan membuat pemahaman produk lebih mudah difahami dan dibuat sesimpel mungkin supaya konsumen lebih memahami tentang manfaatnya Produk-produk herbal lebih aman dan unggul dibandingan produk atau obat yang mengandung bahan kimia agar dapat menarik minat konsumen supaya tertarik untuk menjadi member maupun konsumen produk herbal HNI HPAI.

2. Variasi atau keragaman produk yang di keluarkan HNI HPAI harus dijelaskan secara singkat padat dan jelas agar konsumen tidak salah pemahaman tentang manfaat dan komposisi yang terkandung dalam setiap produk, dengan kata lain dalam katalog atau brosur di tuliskan banyaknya manfaat yang di berikan hanya dalam satu varian produk, agar konsumen tertarik untuk mencoba produk tersebut karena hanya dalam satu produk mempunyai banyak manfaat yang dapat diberikan.

\section{E. DAFTAR RUJUKAN}

Ali, Hasan . 2013. Marketing dan KasusKasus Pilihan. Yogyakarta. CAPS (CenterForAcademicPublishingSer vice)

Ali, Hasan. (2014). Marketing dan Kasus-Kasus Pilihan. CAPS. Yogyakarta
Chaffey Dafe. (2009). E-Business and e-commerce management : strategy Implimentation, and practice. Edition, Printece Hall.

Dennis. 2014. fungsi e-marketing sebagai alat bantu perusahaan dalam segmentasi pasar. makalah. dikutip dari https://www.academia.edu/3706581 3/metolit _nanang_aditya_15101202_.doc 20 mei.

Diansyah, Ayu Indah Nurnalasari. 2017. Pengaruh Pemasaran Internet Dan Electronic Word Of Mouth Terhadap Keputusan Pembelian. Journal Of Business Studies. 2 (1) :84-98

El-Gohary, Hatem. (2010). E-Marketing A literature Review from a Small Businesses perspective

Heikkinen, Henriikka. 2012. Sosial Media and Internet Marketing's Influence On Decision Making Process Of German Nature Tourists".4(1):1-8. Hermawan, Agus. 2012. Komunikasi

Hayatun Isqo . 2015. Pengaruh Variasi Produk Terhadap Volume Penjualan Merek Ako Pada Matahari Departemen Store Lembuswana Di Samarinda. eJournal Ilmu Administrasi Bisnis. 3 (2): $470-481$

Indra Nurahman.2016. Pengaruh Variasi Produk Terhadap KeputusanPembelian. Journal of Business Management and Enterpreneurship Education. 1 (1): $54-63$

Kotler, Philip and Gary Armstrong. 2008. Prinsip-prinsip Pemasaran. Edisi12. Jilid 1. Jakarta: Erlangga. 
Jurnal Kompetitif, Vol. 10, No. 1, hal. 29 - 36, Edisi Januari 2021

p-ISSN 2302-4585; e-ISSN 2721-3765

Kotler, Philip dan Gary armstrong, 2009,

Prinsip-Prinsip Pemasaran, Edisi 12, jilid 2, Jakarta: Erlangga.

Kotler, Philip dan Kevin Lane Keller, 2008. Manajemen Pemasaran, Jilid1,Penerbit Erlangga. Jakarta.

Kotler, dan Keller. (2012). Manajemen

Pemasaran. Edisi 12. Jakarta:

Erlangga 